Research Article

\title{
Application of 3D Laser Scanning in Underground Station Cavity Clusters
}

\author{
Li Pinpin $\mathbb{D}^{1},{ }^{1}$ Qiu Wenge $\mathbb{D}^{1,2}$ Cheng Yunjian, ${ }^{3}$ and Lu Feng $\mathbb{D}^{4}$ \\ ${ }^{1}$ Key Laboratory of Transportation Tunnel Engineering, Ministry of Education, Southwest Jiaotong University, \\ Chengdu 610031, China \\ ${ }^{2}$ Chengdu Tianyou Tunnelkey Co., Ltd., Chengdu 610031, China \\ ${ }^{3}$ School of Civil Engineering and Geomatics, Southwest Petroleum University, Chengdu 610500, China \\ ${ }^{4}$ School of Emergency Science, Xihua University, Chengdu 610039, China \\ Correspondence should be addressed to Qiu Wenge; qiuwen_qw@163.com
}

Received 6 September 2020; Revised 15 January 2021; Accepted 27 January 2021; Published 17 February 2021

Academic Editor: Wen-Chieh Cheng

Copyright (c) $2021 \mathrm{Li}$ Pinpin et al. This is an open access article distributed under the Creative Commons Attribution License, which permits unrestricted use, distribution, and reproduction in any medium, provided the original work is properly cited.

Given the shortcomings of the tunnel overbreak and underbreak control and primary support sectional area detection such as the single means, large workload, low efficiency, and poor accuracy, the use of three-dimensional laser technology can solve the above problems. Based on the Badaling Tunnel Great Wall underground station of the Beijing-Zhangjiakou Railway, the 3D laser scanning technology is used to analyze the distribution of the tunnel overbreak and underbreak and the sectional area of the primary support, compared with the total station measurement results. The results showed that the layout of the scanning measurement station should consider the requirements of scanning accuracy, control the station length and scanning incidence angle, and minimize the scanning station length to reduce the scanning error. The majority of the tunnel section was in overbreak, with the overbreak area ranging from $6.22 \mathrm{~m}^{2}$ to $13.17 \mathrm{~m}^{2}$ and the overbreak rate ranging from 0.283 to 0.598 , and the area of underbreak was relatively small; no overexceeded headroom was found in the primary support, and the tunnel vault was not overbreak. The primary support clearance value of the vault is $0 \sim 15 \mathrm{~mm}$, the clearance value of the sidewall is $35 \mathrm{~mm} \sim 40 \mathrm{~mm}$, and the sidewall needs to be secondary shotcrete. The difference value between the 3D laser scanning measurement data and the total station measurement data is within $3 \mathrm{~mm}$, which is within the error range, indicating the validity and reliability of the $3 \mathrm{D}$ laser measurement result.

\section{Introduction}

The overbreak and underbreak are inevitable in the tunnel construction with drilling and blasting method and influence the tunnel construction quality and tunnel economy. Overbreak will lead to tunnel slag quantity and the shotcrete increase in construction; the tunnel underbreak leads to inadequate tunnel headroom and the need for secondary excavation and may again lead to overexcavation, both of which would delay the progress of construction and increase the cost of construction [1]. At the same time, in case of the tunnel overbreak and underbreak being severe, it will have an impact on the stress of the surrounding rocks and the reliability of the tunnel structure [2]. Tunnel primary support clearance monitoring is an important part of lining quality control. The primary support clearance invading the secondary lining limits leads to reducing the thickness of the secondary lining, resulting in the lack of tunnel strength [3]; the primary support invasion limit needs to carry out temporary support reinforcement, radial grouting reinforcement, and even changing the arch, seriously affecting the tunnel construction progress and increasing construction costs [4]. The too large primary support clearance results in secondary lining thickening, increasing lining rigidity and self-gravity and reducing the bending resistance of the lining [5].

The traditional methods for detecting the tunnel overbreak and underbreak and tunnel clearances include close-up photography, total station position measurement, and manual observation [6]. The method of close- 
up photography has to set up a survey station in the tunnel, lay out the survey line, shoot the palm surface with three angles, respectively, to obtain a three-dimensional image, and then compare it with the design excavation section to obtain the tunnel undercut [7]. The total station measures the profile of the section by measuring several points on the same section, and individual data were obtained to estimate the tunnel overbreak and underbreak condition of the newly excavated section. The traditional method has shortcomings such as a large measuring workload, a small number of points, low accuracy, and poor efficiency. Artificial observation is a supplementary method to the above methods, which is more subjective and requires more experience in tunnel construction. The comparison between 3D laser scanning technology and traditional tunnel measurement methods is shown in Table $1[8,9]$.

3D laser scanning is increasingly used in tunnel engineering $[10,11]$, but less research has been done in underground station construction, and application research in underground station cavity groups in high-speed rail tunnels has not been involved, and this paper has great engineering reference significance. This paper uses the FARO Focus 3D S120 3D scanner system.

\section{Engineering Background}

The new Beijing-Zhangjiakou Railway is a key construction project planned and implemented by the state with a total length of $173.964 \mathrm{~km}$, which is the eastern section of the Beijing-Lanzhou channel, one of the eight longitudinal and eight transverse channels. Badaling Great Wall Station is located in the new Badaling tunnel of the JZSG-3 section of the railway. The geographical location of Badaling Great Wall Station is shown in Figure 1.

The total length of the station is $470 \mathrm{~m}$, the underground construction area is $36,000 \mathrm{~m}^{2}$, and the total length of the equipment cave group is $7190 \mathrm{~m}$. The transition between station and tunnel is realized through the large-span transition section from double line to four lines at both ends of Badaling Great Wall Station. The length of the transition section of the station is $163 \mathrm{~m}$; the maximum cross-sectional area of the station and tunnel is $494.4 \mathrm{~m}^{2}$ with a maximum span of $32.7 \mathrm{~m}$ and height of $19.5 \mathrm{~m}$. The distribution of cave chamber groups in Badaling Great Wall Station is shown in Figure 2. The large-span transition section has poor surrounding rocks, which makes the construction extremely difficult.

\section{3D Laser Application Solutions}

In this paper, Faro Focus 3D 120 3D laser scanner is used, which has an external velocity of 20 meters every 3 minutes, and the laser emission density has 976000 points per second. The measurement time per station is 2 to 5 minutes with an accuracy of $2 \mathrm{~mm}$ (10\% reflectance) and an accuracy of $0.6 \mathrm{~mm}$ (90\% reflectance) when the angle of incidence is zero at $25 \mathrm{~m}$. The scanning radius range is $0.6 \mathrm{~m} \sim 150 \mathrm{~m}$. However, the farther the distance and the more sparse the scanning point cloud, the lower the accuracy is. The scanning frequency is $122-976 \mathrm{~Hz}$, and the laser parameters are $905 \mathrm{~nm}, 20 \mathrm{MW}, 3 \mathrm{R}$ class. The specific parameters of the scanner are shown in Table 2.

The 3D laser scanning system includes (see Figure 3) a 3D laser scanner (a), a special tripod (b), two ball prisms (c), and four splicing spheres (d). 3D laser scanner system through the total station is used to measure the ball prisms target, to achieve the positioning of the global 3D scanning data, with $3 \mathrm{D}$ coordinate positioning, to facilitate the later point cloud data to splice accurately, and compare with cross-sectional data. The splicing spheres are used as the positioning reference point, and the positioning accuracy is $0.1 \mathrm{~mm}$.

\subsection{D Laser Scanning Programs}

3.1.1. 3D Laser Scanning Application Process. The laser point cloud data of the underground station outline were collected, locating the absolute coordinates of target 1 with the total station. The distance between the scanning stations is $40 \mathrm{~m}$, and the scanning time is $2 \sim 5 \mathrm{~min}$. Importing of absolute coordinates of position targets, stitching multisite tunnel point cloud data initializing, and compressing the underground station point cloud data were carried out. Processing point cloud data, generating tunnel overbreak and underbreak cloud map and tunnel headroom detection cloud map, generating reports automatically were carried out.

TK-PCAS is a tunnel laser scanning information system developed by Chengdu Tianyou Tunnelkey Co., Ltd., which has been successfully applied to many railway tunnel projects, including the Badaling Tunnel of the Beijing-Zhangjiakou High-Speed Railway and the Yujingshan Tunnel of the Chengdu-Guizhou Railway. The application process of 3D laser scanning in underground station tunnels is shown in Figure 4.

3.1.2. 3D Laser Scanning Field Measurements. The schematic diagram of the $3 \mathrm{D}$ scanner scanning station is shown in Figure 5. The real coordinates of the reference point are known, and the absolute coordinates of the positioning target are determined through the total station release to the positioning target 1 . The purpose of the positioning target is to provide absolute coordinates for the laser point cloud; while the positioning sphere is for the point cloud data collected by the adjacent scanning station to be quickly and accurately spliced, the positioning target 1 should be within the measuring range of the scanning station 1 and scanning station 2, and the new positioning target 2 should be arranged after the scanning station 2 ; through the point cloud of the scanning station 2 , the relative position relationship between the target 1 and the target 2 can be determined, to determine the absolute coordinates of the positioning target 2 coordinates.

The detailed steps of 3D laser scanning field measurement are as follows: 
TABLE 1: Comparison of 3D laser and conventional measurement methods.

\begin{tabular}{|c|c|c|c|c|c|}
\hline Method & Measurement efficiency & Measurement accuracy & Data format & $\begin{array}{l}\text { Working } \\
\text { intensity }\end{array}$ & $\begin{array}{l}\text { Lighting } \\
\text { conditions }\end{array}$ \\
\hline 3D laser & $\begin{array}{l}\text { Millions of point clouds in } \\
\text { seconds }\end{array}$ & Millimeter class, high accuracy & 3D point cloud & Lower & $\begin{array}{c}\text { Not } \\
\text { demanding }\end{array}$ \\
\hline $\begin{array}{l}\text { Close-up } \\
\text { photography }\end{array}$ & $\begin{array}{c}\text { Requires control point layout, } \\
\text { more efficient }\end{array}$ & Less accurate & $\begin{array}{l}\text { High-definition } \\
\text { pictures }\end{array}$ & $\begin{array}{l}\text { Relatively } \\
\text { low }\end{array}$ & Demanding \\
\hline Total station & $\begin{array}{l}\text { Slow measurement speed, needs } \\
\text { to lay out measurement points }\end{array}$ & $\begin{array}{l}\text { The large spacing of sample } \\
\text { points, low interval accuracy }\end{array}$ & $\begin{array}{l}\text { Measured point } \\
\text { coordinates data }\end{array}$ & $\begin{array}{l}\text { Relatively } \\
\text { high }\end{array}$ & $\begin{array}{c}\text { Not } \\
\text { demanding }\end{array}$ \\
\hline $\begin{array}{l}\text { Manual } \\
\text { observation }\end{array}$ & Varying from person to person & $\begin{array}{l}\text { Varying from person to } \\
\text { person, with poor accuracy }\end{array}$ & None & $\begin{array}{l}\text { Relatively } \\
\text { low }\end{array}$ & Demanding \\
\hline
\end{tabular}

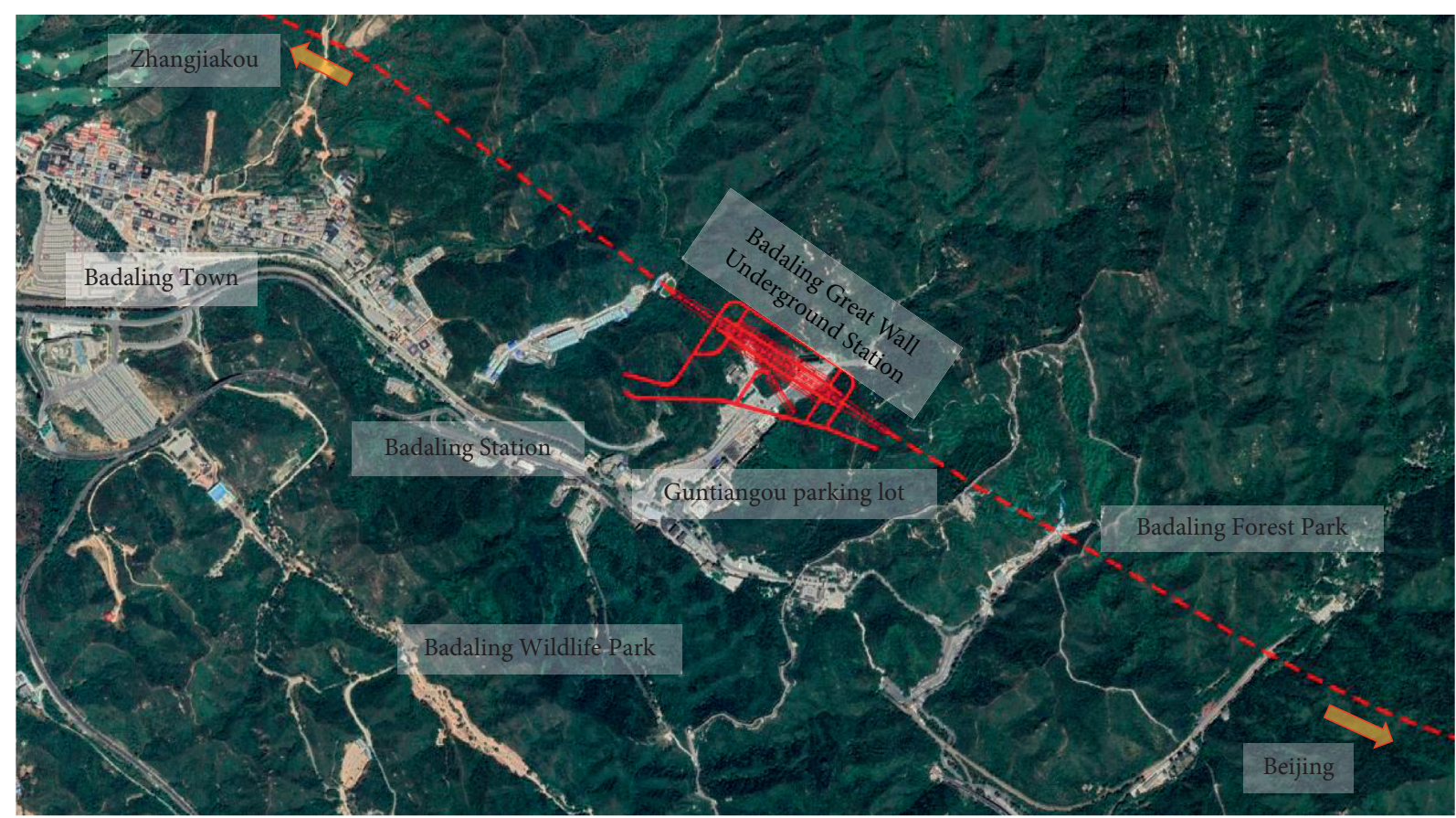

FIGURE 1: Location of Badaling Great Wall Station.

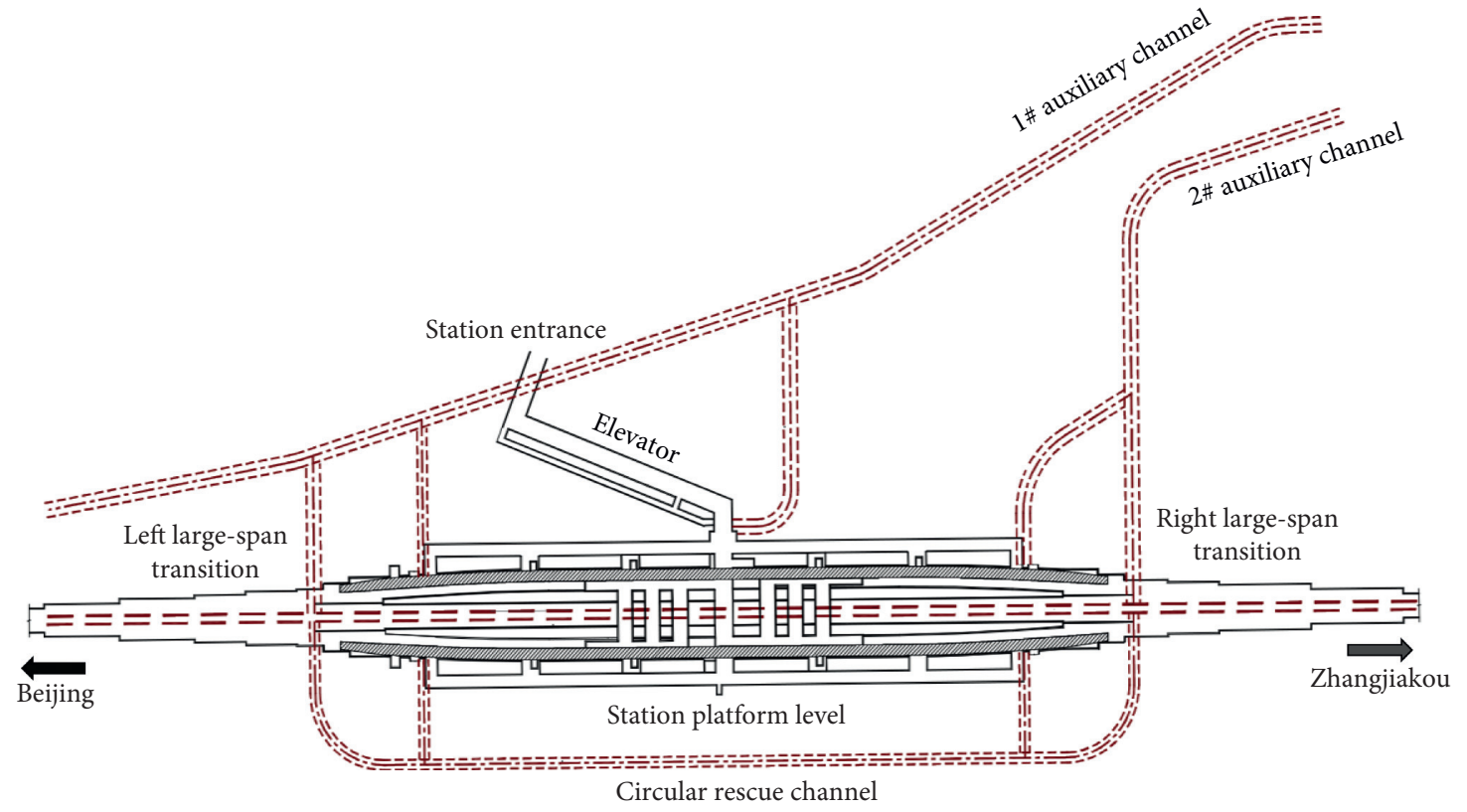

Figure 2: Distribution of caverns at the great wall station. 
TABLE 2: FARO Focus 3D parameter indicators.

\begin{tabular}{lccccc}
\hline Items & Accuracy $(25 \mathrm{~m})$ & Scan frequency & Horizontal field & Vertical field & Scan time \\
\hline Value & $2 \mathrm{~mm}$ & $500 \mathrm{~Hz}$ & $360^{\circ}$ & $305^{\circ}$ & $2 \sim 5 \mathrm{~min}$ \\
\hline
\end{tabular}

Note. There is a positive correlation between scanning accuracy and 3D laser dot density: the larger the 3D laser dot density, the higher the scanning accuracy, and the lower the scanning speed. The parameters in this paper only represent the applicable parameters of the project.

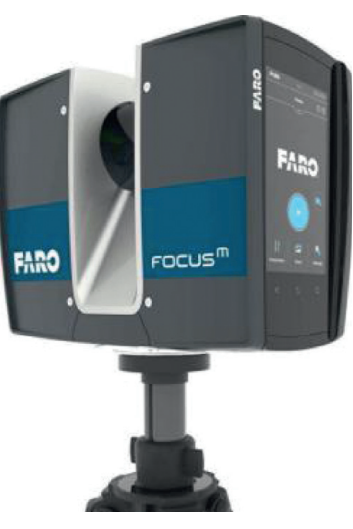

(a)

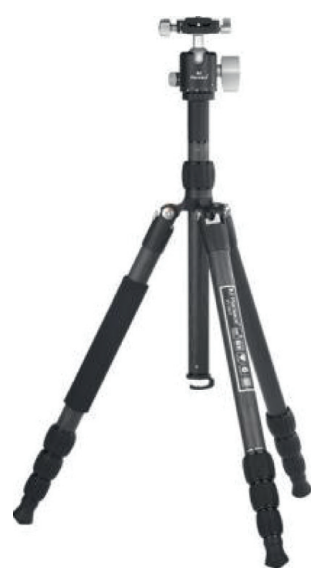

(b)

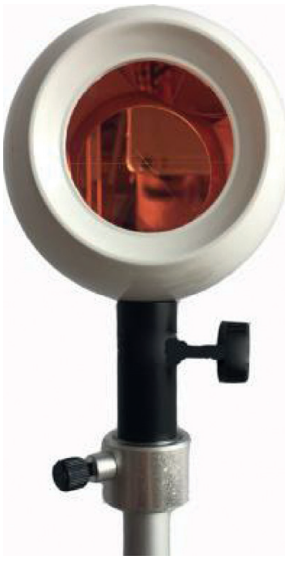

(c)

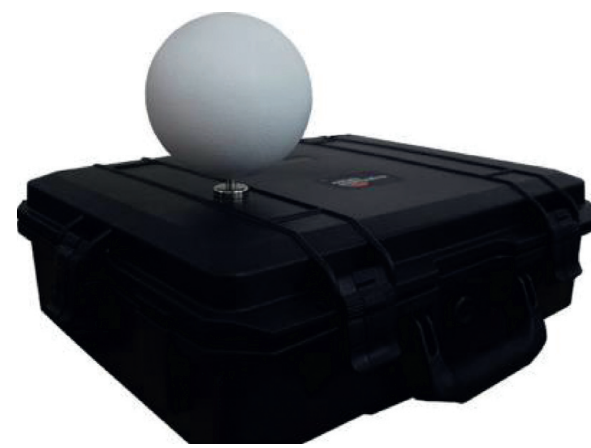

(d)

FIGURE 3: 3D laser scanning system instrumentation.

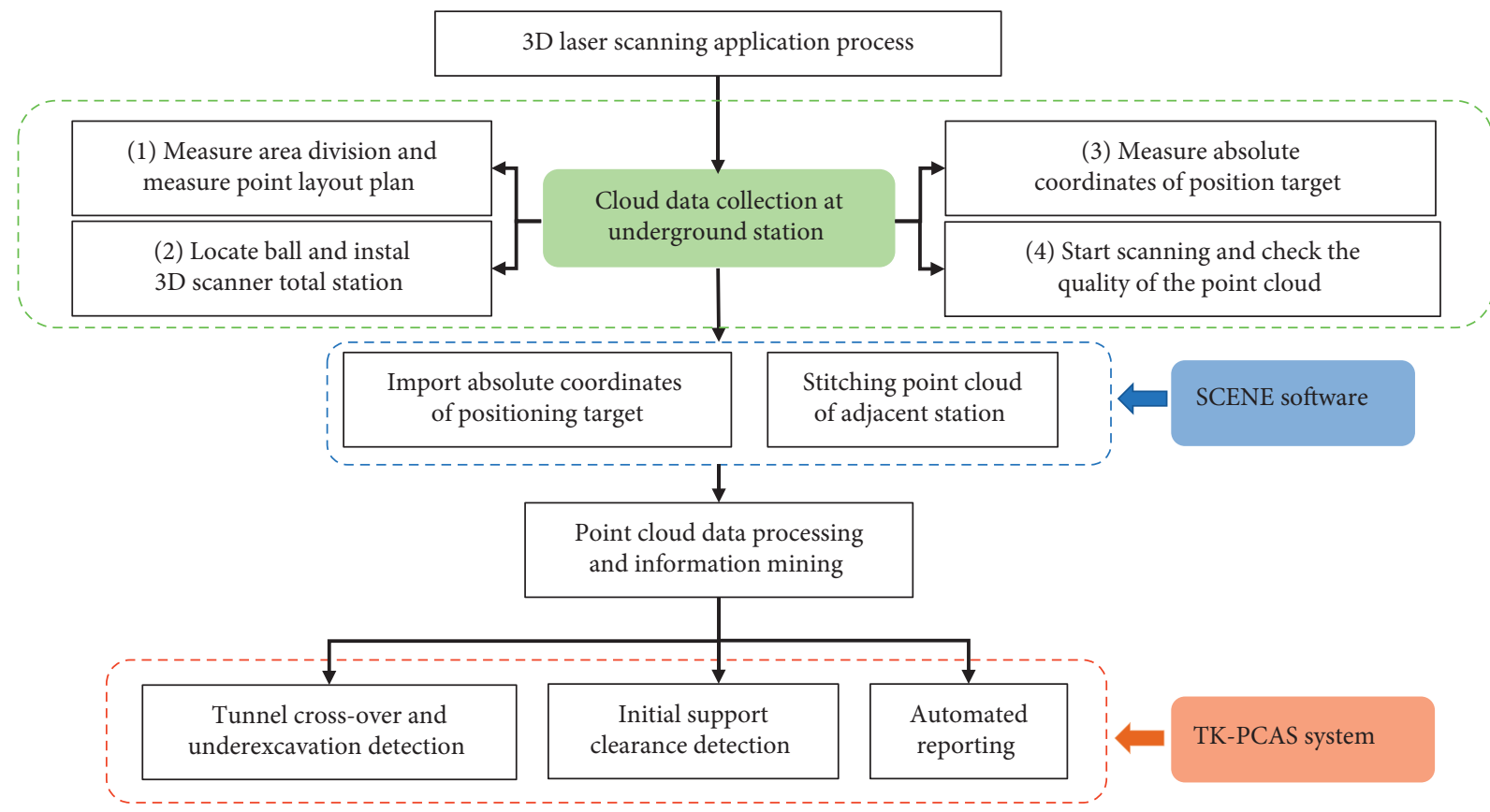

FIGURE 4: 3D scanner scanning application flow.

Step 1. Place the positioning target 1 at the hole of the station to be measured, draw a survey line from the coordinate reference point outside the station to be measured to target 1 , and determine the absolute coordinates of target 1 .

Step 2. Set up the scanning survey station 1 at $20 \mathrm{~m}$ in the measuring direction of the hole and set up the FARO Focus 3D 120; the positioning balls 1 and 2 are placed on both sides at $40 \mathrm{~m}$ in the measuring direction of the hole; to make the later identification convenient, there should be a certain height difference between the two balls.

Step 3. Turn on the laser scanner and start to measure, and after the laser beam is scanned 360 degrees horizontally, the measurement is completed; save the $3 \mathrm{D}$ point cloud data and check the station point cloud map on the display. 


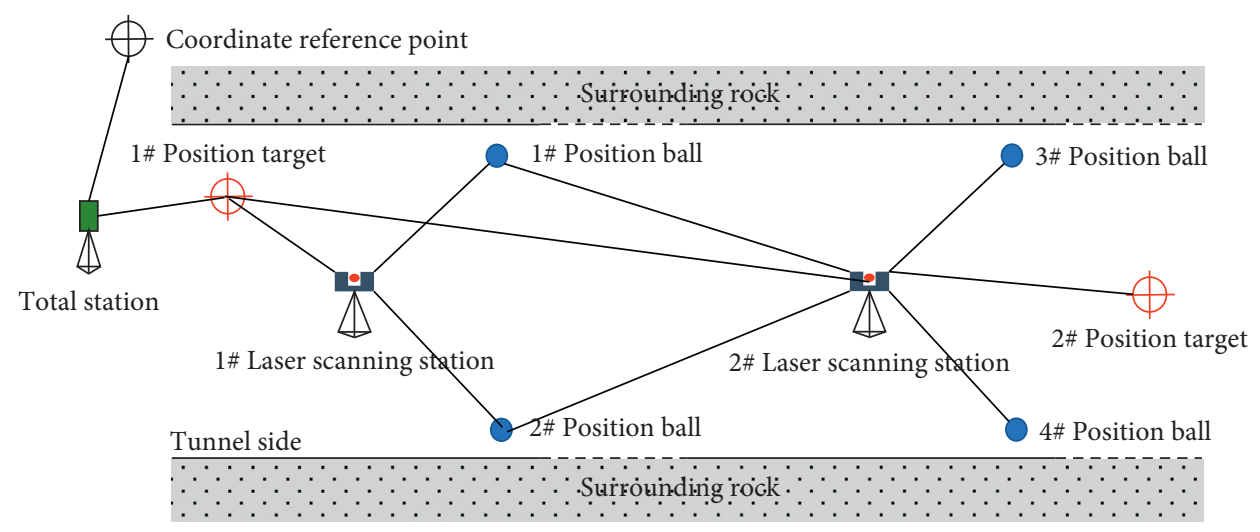

FIGURE 5: Schematic diagram of the 3D scanner scanning station.

Step 4. Measure station 1 after the completion of the scan, the laser scanner along the scanning forward direction to move $40 \mathrm{~m}$; set to scan the measuring station 2, in the measurement direction to continue to advance $20 \mathrm{~m}$ on both sides placed positioning ball 3 and positioning ball 4, positioning ball 1 and positioning ball 2 to remain in place.

Step 5. Continue the measurement, save the $3 \mathrm{D}$ point cloud data, and check the station point cloud map again.

Step 6. Repeat the above steps until the interior contours of the station are completely scanned.

3.1.3. 3D Laser Scanning Station Distribution. Since a tunnel is a narrow, closed space structure, the use of a $3 \mathrm{D}$ laser scanner for tunnel section scanning should fully consider the uneven distribution of tunnel point clouds. Reasonable station planning can reduce its impact on point accuracy. At the same time, factors such as operation cost should also be considered.

Based on the design drawing of the Great Wall Station and the layout of the cavern clusters, and considering the factors influencing the scanning accuracy, the underground station is divided into 20 measurement zones and arranged 38 measurement stations (the scanning range of the scanning measurement stations within the same mileage is the scanning measurement zone). The scanner station is located in the center of the measurement area. Figure 6 shows the distribution of scanning zones in the Great Wall Station of Badaling Tunnel.

When the $3 \mathrm{D}$ scanner adopts high-resolution mode, the measurement accuracy at a distance of $20 \mathrm{~m}$ is $2 \mathrm{~mm}$, the measuring zone length $L$ takes $40 \mathrm{~m}$, and the width $H$ is obtained according to the width of the tunnel section projection, wherein the tunnel section projection width of measuring zone 1 is $15 \mathrm{~m}$, and the tunnel section projection width of measuring zone 6 is $8 \mathrm{~m}$. Through calculation, the minimum accuracy of measuring station 1 is $2 \mathrm{~mm}$, which meets the design requirement of minimum accuracy; the width of each of the station layers is $2 \mathrm{~mm}$. Zone layout is the same; the accuracy of each survey area is also basically known; to survey area 6 for example, after the calculation of its minimum accuracy of $3 \mathrm{~mm}$, it fully meets the tunnel construction accuracy requirements.

3.2. 3D Laser Data Processing Optimization. Through the software TK-PCAS tunnel laser scanning information system large quantities of 3D point cloud measurement data automatically process at a speed of fewer than 20 minutes per station, generate laser scanning images, and provide accurate quantitative analysis reports.

3.2.1. Measurement Accuracy Optimization. Scanning station distribution needs to consider the minimum requirements for scanning point accuracy, select the appropriate resolution, station location, and control the scan time in a reasonable range.

The scanning accuracy of a laser scanner is determined by three factors:

(1) Angular resolution $\varphi$ : the angular resolution determines the density of the laser point cloud, in the same measurement distance, the higher the angular resolution, the higher the density of the laser point cloud and the greater the measurement accuracy.

(2) Measurement area size $A$ : the measurement area size includes the length $L$ and width $H$ of the measurement area, which leads to the angle of incidence $\alpha$ and measurement distance $S$ from the scanner to the corner measurement point.

(3) Laser footprint $D$ : the diameter of the laser footprint $D$ will diverge as the measurement distance increases; the farther the measurement distance, the larger the diameter of the laser footprint, and the smaller the measurement accuracy.

The scanner station is located in the center of the measurement area (as shown in Figure 7), and the scanning measurement accuracy of the four corners is the worst. The error in the point occurs with the change of angle following a 


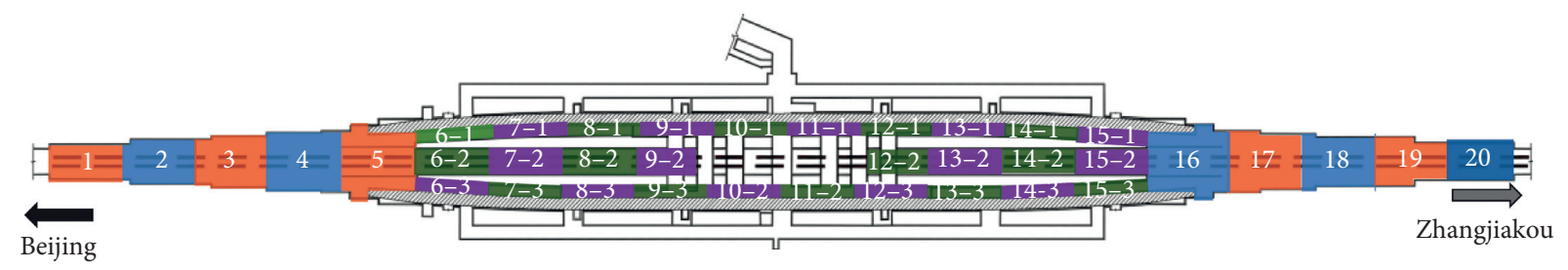

FIgURE 6: Scan survey area delineation at the Great Wall Station.

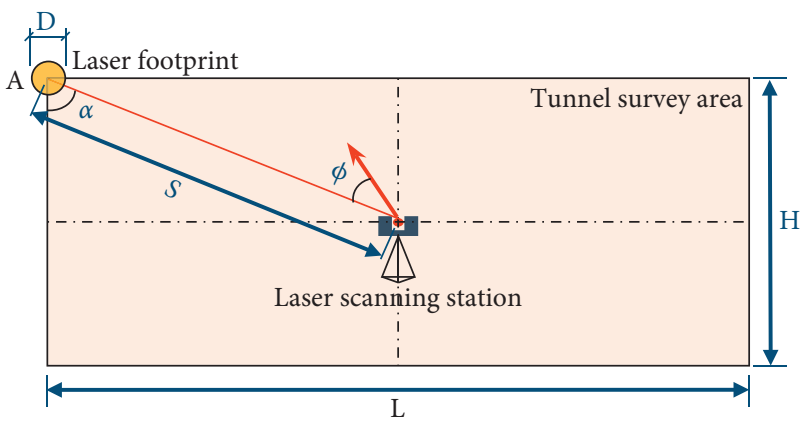

Figure 7: Schematic diagram of scanner measurement accuracy.

certain law, and the error variation has a certain limit value; When the angle of incidence is fixed, the error in the point grows linearly with the growth of the measurement distance [12]. When the incidence distance is fixed and the effect of the incidence angle on the measurement accuracy is considered, the error in the point cloud is

$$
\bar{\sigma}_{p}=\frac{\sigma_{p}}{\cos \alpha}
$$

where $\alpha$ is the scan angle of incidence; $\bar{\sigma}_{p}$ is the error in the point cloud at an incidence angle of $\alpha$; and $\sigma_{p}$ is the error in the point cloud at an incidence angle of 0 .

Assuming that the tunnel contour is a rectangular inground projection as shown in the figure, the FARO laser scanner is located at the intersection point of the tunnel center axis, and the measurement point with the largest angle of incidence is located at corner point $A$. The maximum scanning angle of incidence within the measurement station range is

$$
\alpha_{\max }=\arctan \left(\frac{L}{H}\right)
$$

where $\alpha_{\max }$ is the maximum angle of scan incidence within the range of this station; $L$ is the length of the tunnel profile projection, called the station length; and $H$ is the width of the tunnel profile projection. The higher the laser reflectance, the greater the laser accuracy. The following figure shows the accuracy of tunnel measurement when the laser reflectance is $10 \%$ and $90 \%$, respectively.

Figure 8(a) shows the three-dimensional view of point cloud scanned by laser obtained by Javier Roca-Pardiñas [13]. Figure 8(b) shows the expansion of the laser-scanned point cloud along the midline of the tunnel. The tunnel is a circular section with a radius of $5 \mathrm{~cm}$, and the $3 \mathrm{D}$ laser scanner is located in the middle line of the tunnel. The figures reveal that within the range of $20 \mathrm{~m}$ scanning station, the distribution of point cloud density is not uniform. The point cloud density at the section where the scanner is located is the largest, and the density of the four angular point clouds farthest from the scanner is the smallest.

Delaloye [14] suggested the station spacing $L=H$, and according to equation (2), $\alpha=45^{\circ}$. From Figure 9(a), it can be seen that the tunnel should be within $25 \mathrm{~m}$ of the laser measurement distance under unfavorable conditions $(10 \%$ reflectivity) to meet the scanning accuracy requirements. It is known from equation (2) and Figure 9(b) that the error only starts to rise sharply when the angle of incidence is greater than $65^{\circ}$. When $\alpha=65^{\circ}, L=2.1 \mathrm{D}$. Due to the actual tunnel construction site conditions, the laser scanner may not be set up exactly at the center axis of the tunnel, so the station spacing is recommended to take $L=(1 \sim 2) D$.

3.2.2. Point Cloud Noise Optimization. Due to the poor air quality, high dust density, large particles in the tunnel, and the presence of construction personnel and construction machinery, there are natural noise points in the laser scan. Measuring instruments will produce a series of errors in the process of collecting data, and the $3 \mathrm{D}$ laser scanner is no exception; its collected point cloud data contains unwanted redundant points and noise points mixed with the effective point cloud. The redundant points and noise will not only multiply the amount of point cloud data but also affect the application of point cloud data. Therefore, for the characteristics of underground station cavities, the optimization research of point cloud denoising is carried out based on KD-Tree topology and neighborhood search technology.

(1) KD-Tree Topology and Neighborhood Search. At present, there are two main methods for constructing point cloud neighborhoods: constructing Euclidean neighborhoods by Euclidean distance and constructing $k$-neighborhoods by finding $k$-nearest neighboring points [15]. The point cloud neighborhood search method is only suitable for point clouds with more uniform distribution; the $k$-neighborhood construction by finding $k$-nearest neighbors is suitable for tunneling longitudinal point clouds with uneven density.

The basic principle of $k$-neighborhood search is to calculate the distance from one point to all other points separately and then sort the points in ascending order according to the distance, and finally take the top $k$ points as the $k$-nearest neighbor points of the point. Using KD-Tree to partition the whole point cloud scene makes it more efficient to search the neighboring points in the process of finding the $k$-neighborhood [16]. 


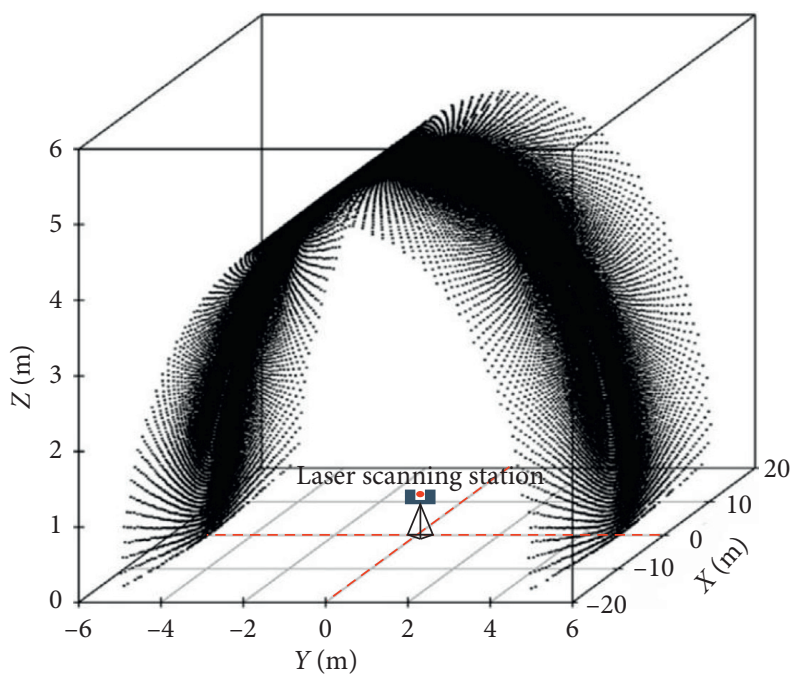

(a)

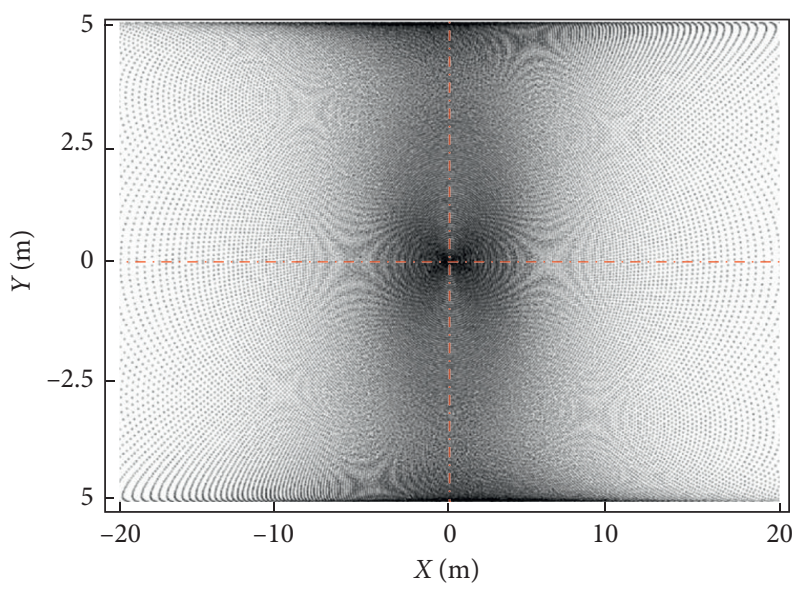

(b)

FIGURE 8: Laser scanning point cloud distribution. (a) Three-dimensional view. (b) Expanded view.

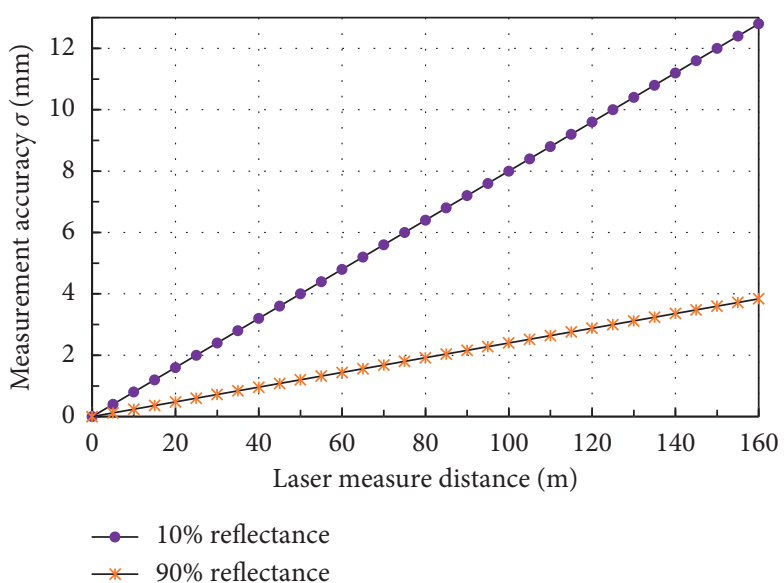

(a)

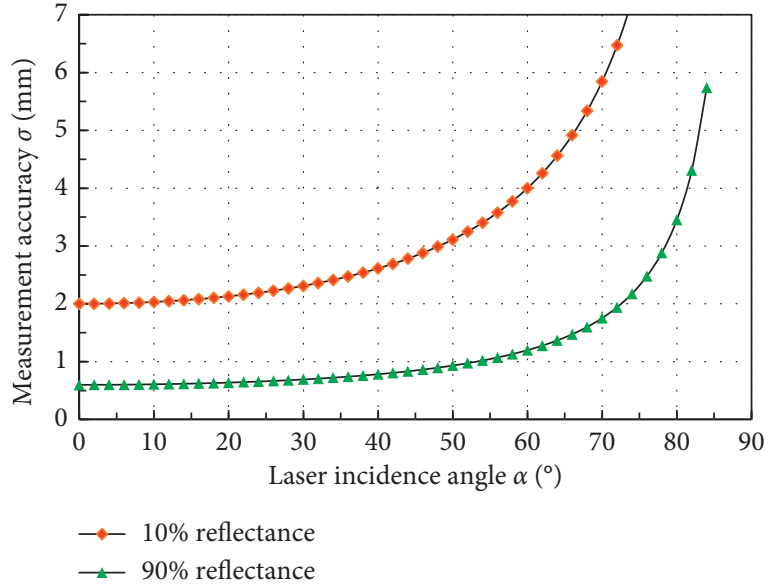

(b)

Figure 9: Variation of measurement accuracy with measurement distance and angle of incidence. (a) Measurement accuracy at different measurement distances. (b) Measurement accuracy at different laser incidence angles.

KD-Tree is a generalized form of searching from binary trees to multidimensional data. $k$ denotes the spatial dimension, so KD-Tree is also called $\mathrm{K}$-dimensional search tree. The quickest way to construct a KD-Tree is to use the splitting method like fast classification by placing the values of the specified dimension on the root node and dividing the remaining points with smaller values than the previous node in this dimension in the left subtree and those with larger values than the previous node in the right subtree. Then, the process is repeated on the left and right subtrees until the last tree of the classification contains only one element.

(2) Laser Cloud Map Noise Reduction Method. The steps of isolated noise filtering in laser point cloud based on KD-tree include organizing the laser point cloud based on KD-tree, finding out the $k$-nearest neighbors, and secondly, filtering out the isolated noise based on the statistical properties of the distance between the isolated noise point and its several $k$-nearest neighbors.

Assuming that the median of the distances of the $k$ nearest neighbors of the laser points approximately satisfies the normal distribution, then $99.73 \%$ of the points will fall in this region (shown in Figure 10), and the points within this range will be regarded as valid points, and only a very few points that do not meet the conditions will fall outside the range, and these points will be regarded as noise points to be removed. By setting the threshold value in this way, the threshold value can be calculated automatically according to the data size, without manual repetition of setting, which improves efficiency and speed.

If the average of the distances of the $k$-nearest neighbors of any laser point $i$ is $D$, then 


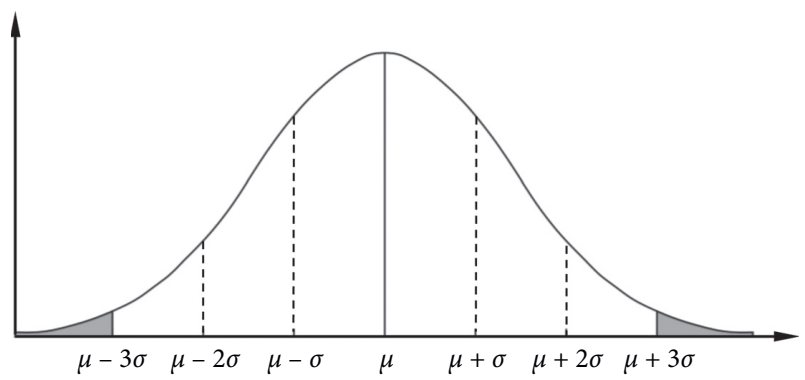

FIGURE 10: Normal distribution curve schematic diagram.

$$
\mu=\sum_{i=1}^{n} D_{i} .
$$

The standard deviation $s$ is

$$
s=\sqrt{\sum_{i=1}^{n} \frac{(D-\mu)^{2}}{n} .}
$$

When $|\mu-3 \sigma| \leq D_{i} \leq|\mu+3 \sigma|$, it is a valid laser point; otherwise, it is an isolated noise point and is automatically filtered out.

(3) Effect of Noise Reduction Optimization. Figure 11 shows the $3 \mathrm{D}$ point cloud image of the tunnel during the operation period. Figure 11(a) shows the 3D scanned raw cloud image, and Figure 11(b) shows the point cloud after the noise reduction process. The noise in the cloud image is mainly construction crew residuals, protruding objects inside the lining, noise on the lining profile section, and other particulate matter that affects the laser imaging. The comparison of the figures before and after filtering shows that all the noise on the tunnel contour disappears, the construction personnel clutter noise also disappears, and the noise in the part connected to the track near the bottom plate also basically disappears, while the effective points on the tunnel contour section are not significantly mistakenly deleted and do not affect the subsequent processing.

\section{3D Laser Scanning Results and Analysis}

4.1. The Tunnel Overbreak and Underbreak Detection. The 3D laser scanning technology evaluated the tunnel overbreak and underbreak, and the accuracy of the tunnel overbreak and underbreak and calculations (including excavation volume, overexcavation volume, the tunnel overbreak and underbreak volume, and effective excavation volume) can reach the millimeter level [6]. Accurate tunnel overbreak and underbreak statistics can provide a reference for the next cycle of drilling and blasting, thus achieving the purpose of controlling overexcavation and avoiding underexcavation.

Data collection frequently constructed tunnels can be limited by several site factors [10]. Laser scanning in dusty tunnels significantly reduces the point cloud quality and the scanner is subject to dust and moisture that affects its service life, so as far as possible, the tunnel excavation profile sections are scanned according to the excavation progress, after blasting, mechanical slagging, and manual cleaning.

In this paper, the $3 \mathrm{D}$ laser point cloud data is compared with the excavation design section based on the TK-PCAS system to analyze the over-the-tunnel overbreak and underbreak condition of the tunnel. The actual excavation section is called overexcavation and the tunnel overbreak and underbreak if the contour of the designed tunnel is outside the datum line and inside the datum line. The contours of the design section are known according to the tunnel design documents, and the actual excavation contours are analyzed by the $3 \mathrm{D}$ laser scanning point cloud.

Figure 12 is a scanning cloud map of the excavation profile for the mileage range DK68+455 to DK68+459. Positive values (blue) indicate overbreak and negative values (red) indicate underbreak. Figure 13 shows that the tunnel overbreak and underbreak exists around the excavation contour, with the maximum depth of the tunnel overbreak and underbreak reaching $150 \mathrm{~mm}$; a small area of the overbreak and underbreak exists in the center of the vault, with the depth of about $50 \mathrm{~mm}$; most of the tunnel excavation contour is in the state of the overbreak, with the maximum depth of overexcavation reaching $200 \mathrm{~mm}$.

Table 3 shows the tunnel overbreak and underbreak size statistics for sections DK68 + 455 to DK68 + 459 .

The results from Table 3 show that the tunnel cross section is generally in overbreak, with the overbreak area ranging from $6.22 \mathrm{~m}^{2}$ to $13.17 \mathrm{~m}^{2}$ and the overbreak rate ranging from 0.283 to 0.598 . The area of the tunnel underbreak is small, with the tunnel underbreak area ranging from $0.15 \mathrm{~m}^{2}$ to $0.43 \mathrm{~m}^{2}$ and the underbreak rate was between 0.007 and 0.019 .

4.2. Primary Support Clearance Monitoring. After the primary support is constructed for a certain distance (generally $40 \mathrm{~m}$ ), the clearance of the tunnel can be scanned and inspected. After the scanning point cloud data is processed, the primary support surface contour cloud map is obtained. Through comparatively analyzing the point cloud contour surface and the design section of the primary support (including reserved deformation amount), the primary support clearance cloud map is obtained. Positive clearance values indicate that the point cloud profile is inside the design section of the primary support and has not reached the design limit. Negative clearance values indicate that the point cloud profile is outside the design section of the primary support.

Figure 14 shows the $3 \mathrm{D}$ scan data of the primary support clearances in the cross section of the mileage range $\mathrm{DK} 68+409 \sim 449$. The 3D laser scan point cloud is shown in Figure 14(a) below, and the primary support clearances are shown in Figure 14(b). Figure 15 shows the expanded view of primary support clearances' scanning cloud map.

As we can see in Figure 15, the point cloud profile is inside the design section of the primary support (clearance is positive), the sectional area value is $0 \sim 15 \mathrm{~mm}$ in the vault, and the clearance value is larger in the sidewall of primary support, which is $35 \sim 40 \mathrm{~mm}$, and the secondary shotcrete is needed in the sidewall. The ground part is out of the scope of analysis. 


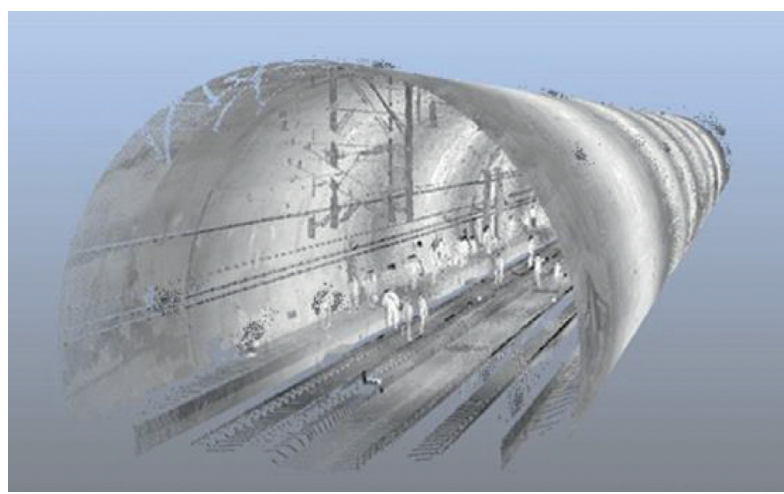

(a)

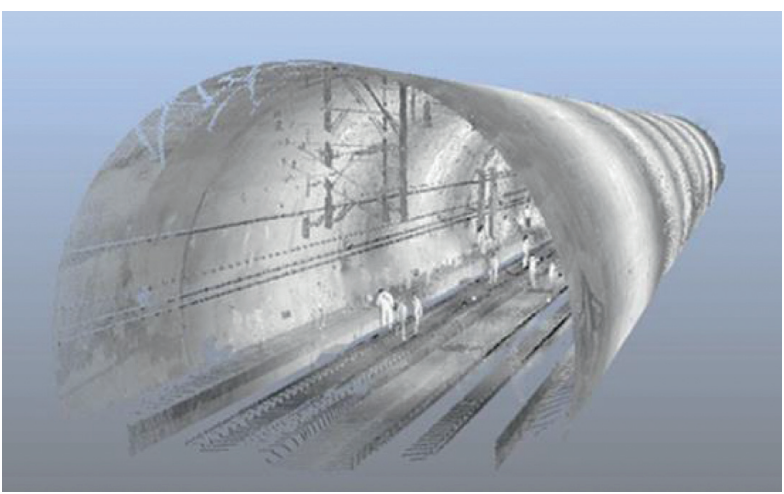

(b)

Figure 11: Noise reduction processing effect. (a) Original cloud map. (b) Noise reduction cloud map.

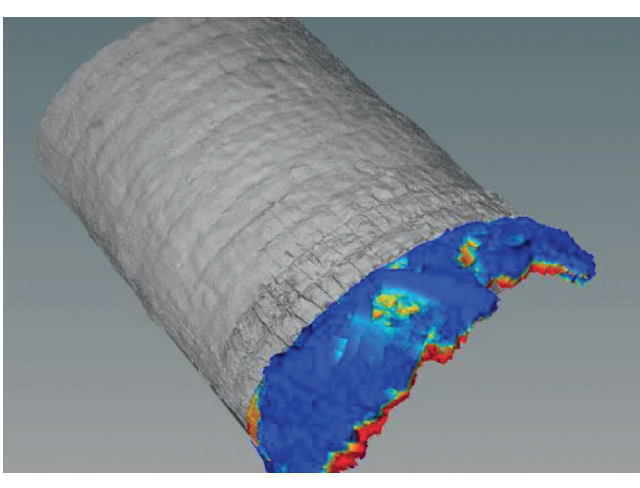

(a)

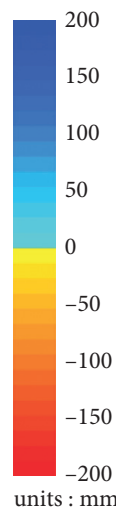

units : $\mathrm{mm}$

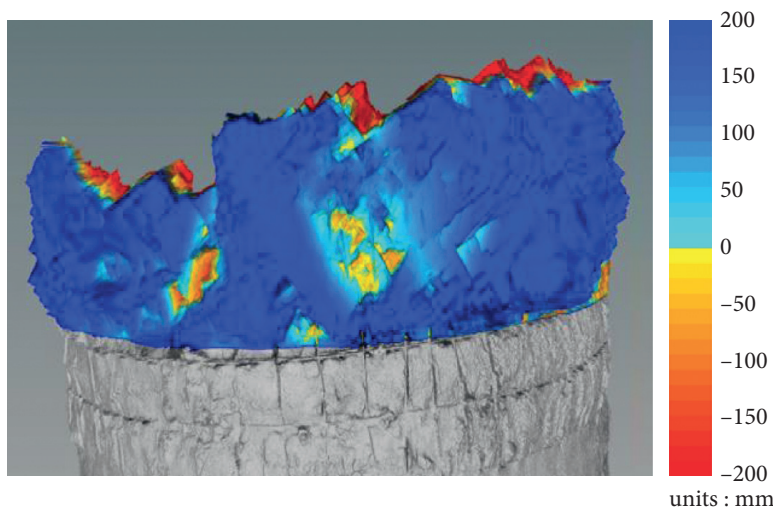

(b)

FiguRE 12: The tunnel overbreak and underbreak scanning. (a) Side view. (b) Front view.

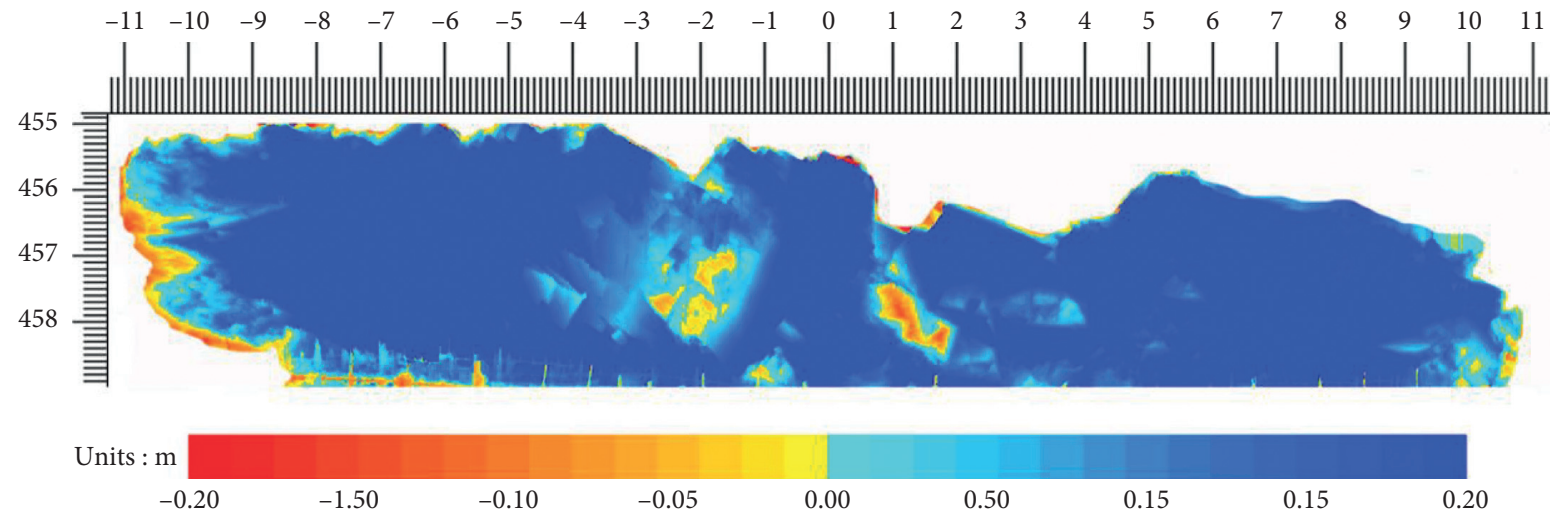

Figure 13: Expanded image of the tunnel overbreak and underbreak scanning.

According to the construction site conditions, a monitoring section is arranged at an interval of $10 \mathrm{~m}$ at the surface of the primary support of the tunnel, and 5 measurement points are arranged symmetrically at each monitoring section, which is located at the top of the arch, left arch foot, right arch foot, left wall, and right wall. The measurement results of the mileage range of DK68 + 410 DK68 +449 are shown in Figure 16. 3D laser scanning can obtain the complete cross section of the outline of the sectional area, while the total station is only measuring a limited number of points, the tunnel clearance values are positive; that is, the tunnel overall outline did not intrude into the secondary lining design section. The clearance value in the vault is smaller, followed by the arch foot on both sides, and the primary support at the side walls has the largest clearance value. 
TABLE 3: Statistical table of the tunnel overbreak and underbreak dimensions.

\begin{tabular}{lccccccc}
\hline Mileage range & $\begin{array}{c}\text { Design area } \\
\left(\mathrm{m}^{2}\right)\end{array}$ & $\begin{array}{c}\text { Overbreak area } \\
\left(\mathrm{m}^{2}\right)\end{array}$ & $\begin{array}{c}\text { Overbreak } \\
\text { Overbreak } \\
\text { volume }\left(\mathrm{m}^{3}\right)\end{array}$ & $\begin{array}{c}\text { Overbreak } \\
\text { rate }\end{array}$ & $\begin{array}{c}\text { Underbreak area } \\
\left(\mathrm{m}^{2}\right)\end{array}$ & $\begin{array}{c}\text { Underbreak } \\
\text { Underbreak } \\
\text { volume }\left(\mathrm{m}^{3}\right)\end{array}$ & $\begin{array}{c}\text { Underbreak } \\
\text { rate }\end{array}$ \\
\hline DK455 DK456 & 22 & 6.22 & 0.51 & 0.283 & 0.15 & 0.08 & 0.007 \\
DK456 DK457 & 22 & 8.56 & 0.75 & 0.389 & 0.28 & 0.11 & 0.013 \\
DK457 DK458 & 22 & 11.25 & 0.64 & 0.511 & 0.43 & 0.16 & 0.019 \\
DK458 DK459 & 22 & 13.17 & 0.71 & 0.598 & 0.39 & 0.14 \\
\hline
\end{tabular}

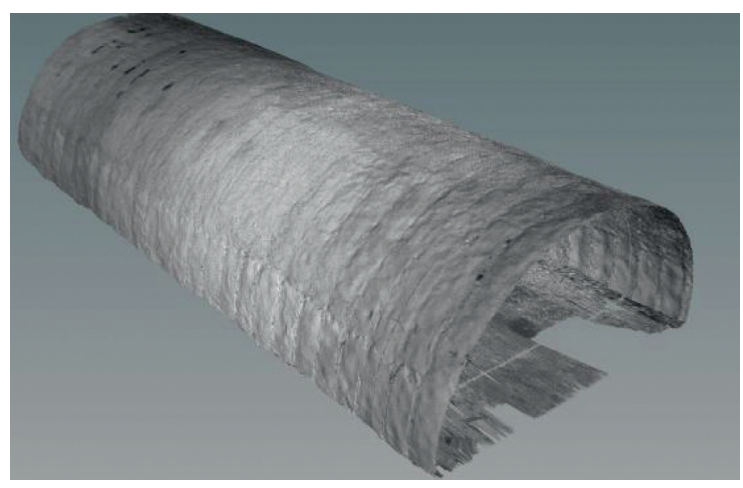

(a)

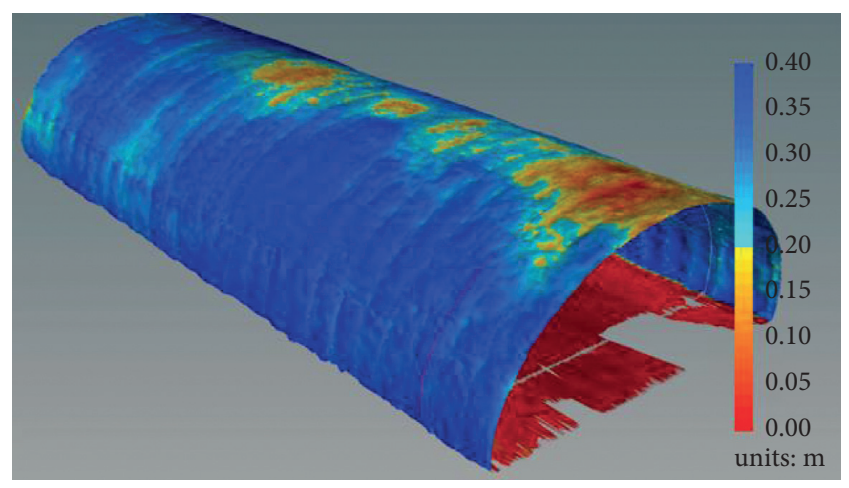

(b)

FIGURE 14: Primary support clearances' scanning cloud map of the tunnel. (a) 3D laser scanning point cloud. (b) Primary support clearances' scanning map.

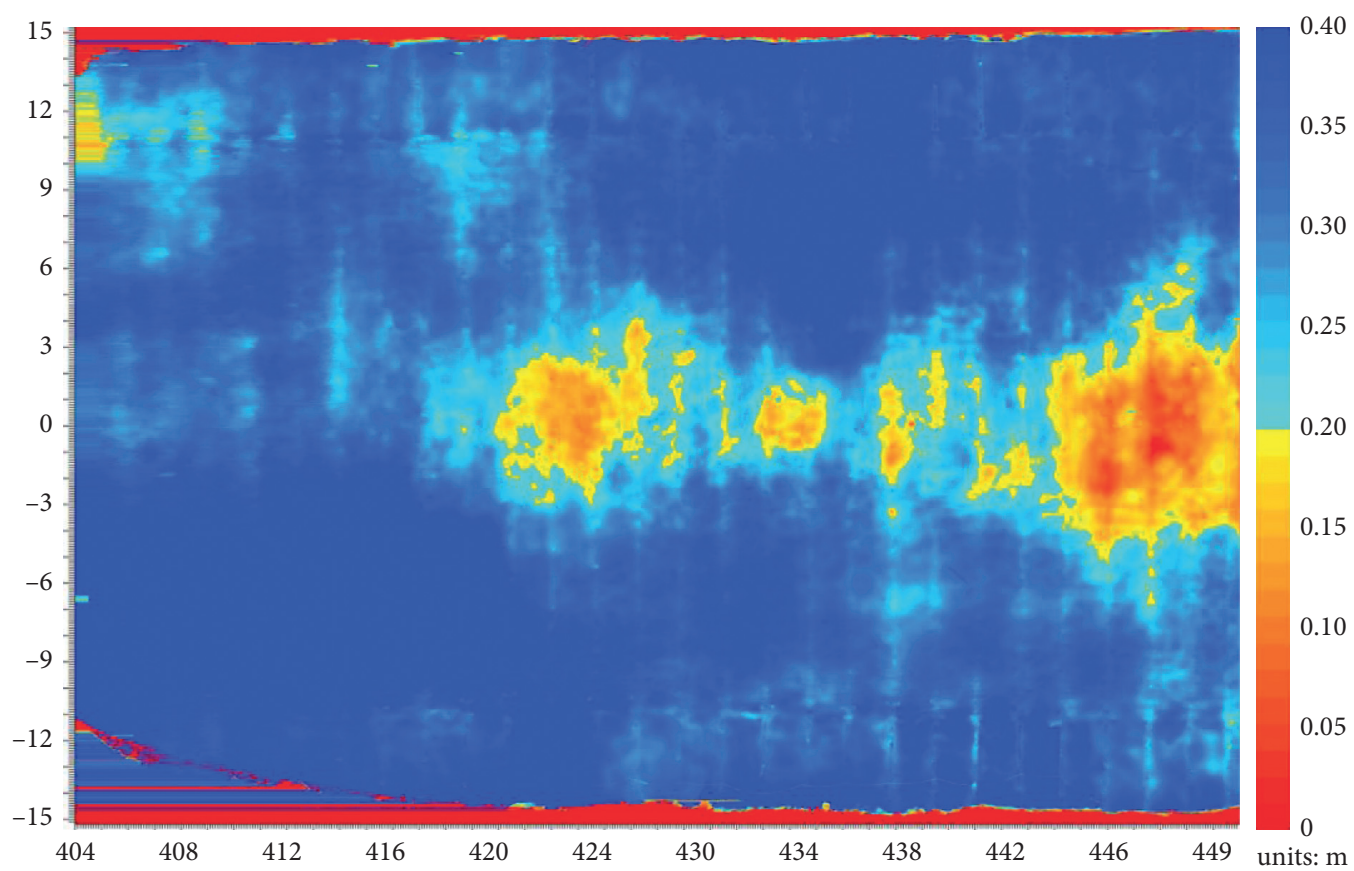

FIgURE 15: Expanded view of primary support clearances' scanning cloud map.

As we can see from Table 4, the difference value of 3D laser scanning clearance and the total station measurement date is within $3 \mathrm{~mm}$, which is the largest error location in the left wall, the absolute value of the difference is $2.6 \mathrm{~mm}$, which is the smallest error location in the left arch foot, the absolute value of the difference is 0.4 , and $3 \mathrm{D}$ laser scanning of the clearance value is generally greater than the total station measurement data, because of the difference with the measurement time, The difference reflects the initial deformation of the tunnel, 


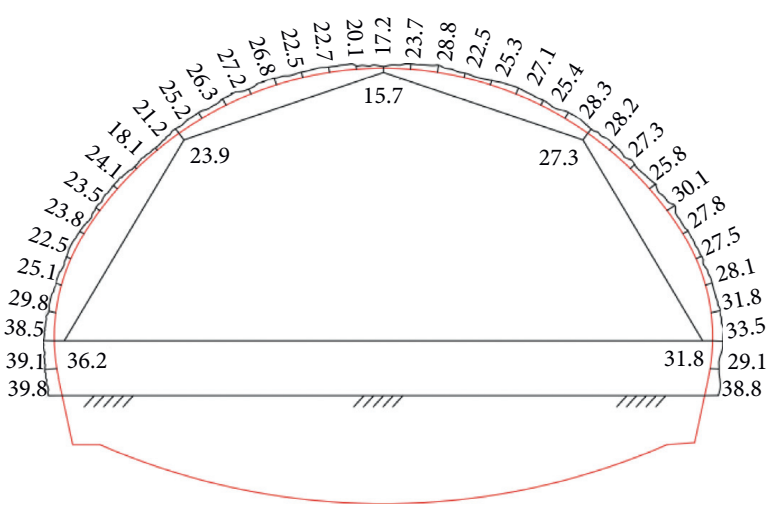

(a)

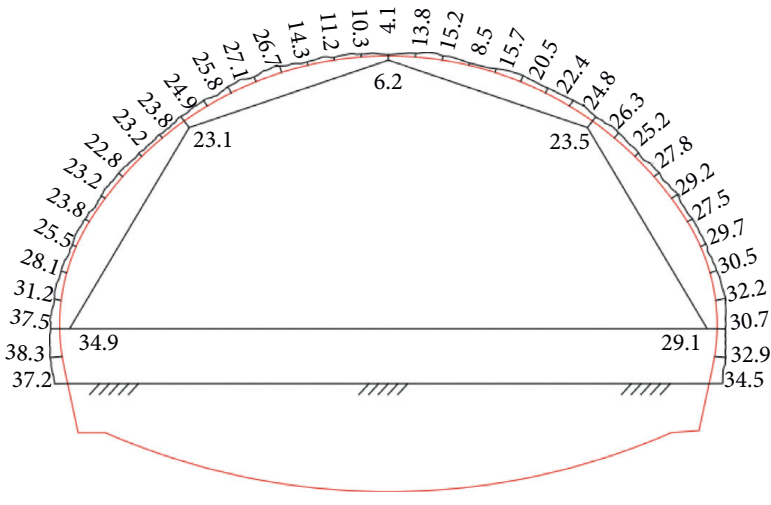

(c)

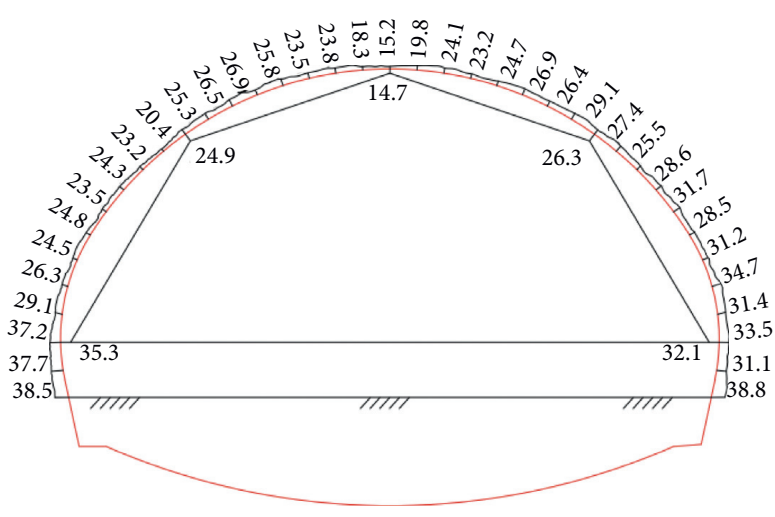

(b)

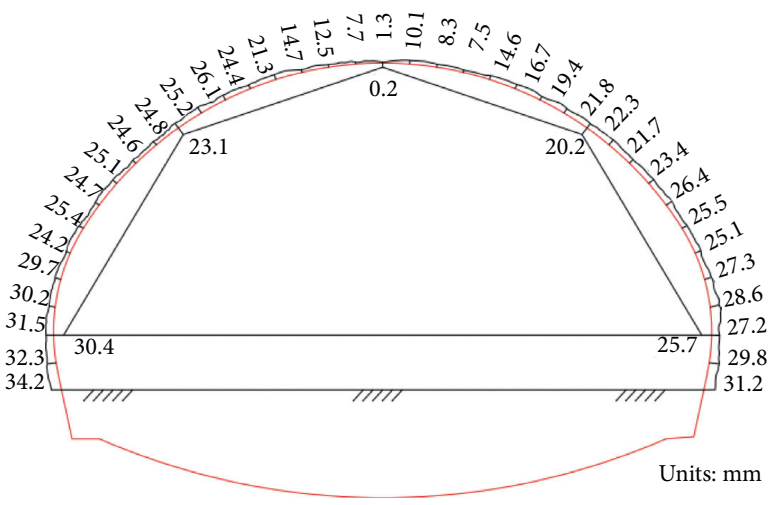

(d)

FiguRE 16: 3D laser scanning and total station section measurement data comparison. (a) DK68 + 415. (b) DK68 + 425 . (c) DK68 + 435. (d) DK68+ 445 .

TABLE 4: Statistical table of primary support clearances of tunnel.

\begin{tabular}{|c|c|c|c|c|c|c|c|c|c|}
\hline \multirow{3}{*}{ Mileage } & \multicolumn{9}{|c|}{ Tunnel clearance $(\mathrm{mm})$} \\
\hline & \multicolumn{3}{|c|}{ Vault } & \multicolumn{3}{|c|}{ Left arch } & \multicolumn{3}{|c|}{ Left wall } \\
\hline & 3D laser & Total station & Difference value & 3D laser & Total station & Difference value & 3D laser & Total station & Difference value \\
\hline DK68 + 415 & 17.2 & 15.7 & 1.5 & 25.2 & 23.9 & 1.3 & 38.5 & 36.2 & 2.3 \\
\hline $\mathrm{DK} 68+425$ & 15.2 & 14.7 & 0.5 & 25.3 & 24.9 & 0.4 & 37.2 & 35.3 & 1.9 \\
\hline DK68 + 435 & 4.1 & 6.2 & -2.1 & 24.9 & 23.1 & 1.8 & 37.5 & 34.9 & 2.6 \\
\hline $\mathrm{DK} 68+445$ & 1.3 & 0.2 & 1.1 & 25.2 & 24.1 & 1.1 & 31.5 & 30.4 & 1.1 \\
\hline
\end{tabular}

which was measured by the total station later than the $3 \mathrm{D}$ laser scan.

\section{Conclusions}

In this paper, $3 \mathrm{D}$ laser scanning technology is investigated as a method for monitoring the tunnel overbreak and underbreak and primary support clearance in the construction of underground station tunnel clusters, and the main conclusions are as follows.

The tunnel structure is a thin and long line structure; scanning station layout considering the specific requirements of scanning accuracy needs to control the station length and scanning incidence angle. To reduce the scanning error, the scanning station length should be reduced; the distance between the two stations is about $40 \mathrm{~m}$, with a station scanning radius of $20 \mathrm{~m}$. There are 4 corners of each measurement area; the worst scanning measurement accuracy, after calculation and analysis of the minimum accuracy of station 1 , is $2 \mathrm{~mm}$. The minimum accuracy of the measuring zone $6 \mathrm{~mm}$ is $3 \mathrm{~mm}$, which fully meets the requirements of tunnel construction accuracy. The station spacing is recommended to take $L=(1 \sim 2) D$.

Based on the TK-PACS system, the tunnel overbreak and underbreak profile can be obtained by comparing the $3 \mathrm{D}$ scan data with the design cross section, and the results show that the tunnel cross section is generally in overbreak, with the overbreak area ranging from $6.22 \mathrm{~m}^{2}$ to $13.17 \mathrm{~m}^{2}$, and the area of the tunnel underbreak is small.

By scanning the tunnel primary support sectional area, we obtained the primary support surface contour cloud map, and the tunnel clearance detection cloud map was obtained. The results showed that the tunnel primary support did not exceed the design section, the clearance value of the vault 
part was $0 \sim 15 \mathrm{~mm}$, and the clearance value of the sidewall was larger, the clearance value was $35 \sim 40 \mathrm{~mm}$, and the sidewall needed to be shotcrete twice.

By the comparison of 3D laser scanning clearance and the total station measurement date, the difference value is within $3 \mathrm{~mm}$, which is within the error margin. The position with the largest error is the left wall with a value of $2.6 \mathrm{~mm}$, and the position with the smallest error is the left arch foot with a value of $0.4 \mathrm{~mm}$.

\section{Data Availability}

The 3D laser data collected and used for analysis will be available from the corresponding author upon request.

\section{Conflicts of Interest}

The authors declare that there are no conflicts of interest regarding the publication of this article.

\section{Acknowledgments}

This work was supported by the Science and Technology Research and Development Project of China Railway Corporation (2017G007-A), National Key R\&D Program of China (2017YFC0806000), and Big Data-Driven Structural Disasters Prediction and Maintenance in Hazardous Geological Regions of Subsea Tunnels (51991395).

\section{References}

[1] D. Liu, W. Gao, and M. Liu, "The cause of excessive or insufficient excavation in tunnel construction and its control," Chinese Journal of Underground Space and Engineering, vol. 3, no. z2, pp. 1468-1471, 2007.

[2] M. Wang and B. Guan, "The statistical rule of tunnel overbreak and its influence on tunnel reliability," Chinese Journal of Geotechnical Engineering, vol. 1, pp. 85-90, 1997.

[3] W. Bo, L. Tianbin, H. Chuan et al., "Model test of effect of lining thinning on tunnel structure bearing capacity," Journal of the China Railway Society, vol. 35, no. 2, pp. 106-114, 2013.

[4] Z. Qin and H. Liang, "The method and significance of crosssection clearance detection before tunnel arch wall lining," Journal of China and Foreign Highway, vol. 1, pp. 125-128, 2007.

[5] F. Jimeng and Q. Wenge, "Model test on the effect of tunnel lining stiffness to structure durability," Journal of Central South University (Science and Technology), vol. 44, no. 9, pp. 3884-3890, 2013.

[6] L. Tao, Q. Wenge, C. Yunjian et al., "Study on tunnel support evaluation system based on holographic deformation monitoring," Chinese Journal of Underground Space and Engineering, vol. 16, no. 2, pp. 583-590, 2020.

[7] T. Shengli, G. Xiurun, and T. Zhijun, "Testing study on digital close-range photogrammetry measuring deformations of tunnel and underground space," Chinese Journal of Rock Mechanics and Engineering, vol. 7, pp. 1309-1315, 2006.

[8] J. Li, Y. Wan, and X. Gao, “A new approach for subway tunnel deformation monitoring: high-resolution terrestrial laser scanning," ISPRS-International Archives of the Photogrammetry, Remote Sensing and Spatial Information Sciences, vol. XXXIX-B5, pp. 223-228, 2012.
[9] K. R. Shoff, “A new approach to tunnel digital geological mapping using 3D terrestrial laser scanning technique paper No.315," Isrm-sponsored International Symposium on Rock Mechanics: "Rock Characterisation Modelling and Engineering Design Methods", International Society for Rock Mechanics \& University of Hong Kong, Hong Kong, China, 2009.

[10] S. Fekete, M. Diederichs, and M. Lato, "Geotechnical and operational applications for 3-dimensional laser scanning in drill and blast tunnels," Tunnelling and Underground Space Technology Incorporating Trenchless Technology Research, vol. 25, no. 5, 2010.

[11] J.-Y. Han, J. Guo, Y.-S. Jiang et al., "Monitoring tunnel deformations by means of multi-epoch dispersed 3D LiDAR point clouds: an improved approach," Tunnelling and Underground Space Technology, vol. 38, pp. 385-389, 2013.

[12] S. Li, Tunnel Continuous Cross-Section Extraction and Deformation Analysis Using Terrestrial ScanningChang'an University, Xi'an, China, 2015.

[13] D. Delaloye, "Development of a new methodology for measuring deformation in tunnels and shafts with terrestrial laser scanning (LiDAR) using elliptical fitting algorithms," Msc Thesis, Queen's University, Kingston, Canada, 2012.

[14] J. Roca-Pardiñas, R. Argüelles-Fraga, F. de Asís López, and C. Ordóñez, "Analysis of the influence of range and angle of incidence of terrestrial laser scanning measurements on tunnel inspection," Tunnelling and Underground Space Technology, vol. 43, pp. 133-139, 2014.

[15] F. F. Zhang, Y. B. Liang, and J. Wang, "The nearest neighbor search filtering of point cloud data based on noise isolation," Engineering of Surveying and Mapping, vol. 27, no.1, pp. 29-33, 2018.

[16] M. F. Song, D. Z. Jia, J. W. Guo et al., "A point cloud compression algorithm based on $\mathrm{k}$ neighborhood cuboid," Science of Surveying and Mapping, vol. 44, no. 10, pp. 93-100, 2019. 